\title{
Chromosome microarray analysis in the investigation of children with congenital heart disease
}

\author{
Xiao-li $\mathrm{Wu}^{\dagger}$, Ru Li ${ }^{\dagger}$, Fang Fu, Min Pan, Jin Han, Xin Yang, Yong-ling Zhang, Fa-tao Li and Can Liao*
}

\begin{abstract}
Background: Our study was aimed to explore the clinical implication of chromosome microarray analysis (CMA) in genetically etiological diagnosis of children with congenital heart disease (CHD).

Methods: A total of 104 children with CHD with or without multiple congenital anomalies (MCA) or intellectual disabilities/developmental delay (ID/DD) but normal karyotype were investigated using Affymetrix CytoScan HD array.

Result: Pathogenic copy number variations (PCNVs) were identified in 29 children (27.9\%). The detection rates in children with simple CHD and complex CHD were $31.1 \%$ (19/61) and 23.2\% (10/43), respectively. The detection rates of PCNVs were 17.9\% (7/39), 20\% (5/25), 63.2\% (12/19) and 23.8\% (5/21) in isolated CHD, CHD plus MCA, CHD plus ID/DD, CHD plus MCA and ID/DD, respectively. The PCNVs rate of CHD plus ID/DD was significantly higher than that of isolated CHD. Two genomic loci including 15q11.2 deletion and 1q43-q44 deletion were considered as CHD locus. The DVL1, SKI, STIM1, CTNNA3 and PLN were identified as candidate genes associated with CHD phenotypes.
\end{abstract}

Conclusion: CMA can increase the diagnostic rate and improve the etiological diagnosis in children with CHD. We suggest CMA as a first-tier test in children with CHD, especially in children with CHD plus ID/DD.

Keywords: 15q11.2 deletion, 1q43-q44 deletion, Chromosome microarray analysis, Congenital heart disease, Copy number variation, Microdeletion/microduplication

\section{Background}

Congenital heart disease (CHD) is one of the most common birth defects. The incidence of CHD in the neonate is 8-9/1000, and nearly 1.35 million CHD neonates were born every year in the whole world [1]. Despite improvement of various treatment measures, $\mathrm{CHD}$ is still one of the major causes of children mortality.

The causes of CHD include non-genetic factors and genetic factors. Non-genetic factors include: environmental factors, maternal exposure and infection. Chromosomal causes of CHD include chromosome aneuploidies, like trisomy 21, and copy number variations (CNVs). Chromosomal aneuploidies represent $12.5 \%$ of $\mathrm{CHD}$

\footnotetext{
* Correspondence: canliao@hotmail.com

${ }^{\dagger}$ Equal contributors

Prenatal Diagnostic Center, Guangzhou Women and Children's Medical Center, Guangzhou Medical University, No. 9 Jinsui Road, Guangdong, China
}

causes [2]. The spectrum of CHD-related $\mathrm{CNVs}$ ranges from recurrent microdeletion and microduplication syndromes, like DiGeorge syndrome (22q11 deletion syndrome) and Williams-Beuren syndrome (7q11.23 deletion syndrome), which are associated with a distinct clinical recognizable phenotype, to rare $\mathrm{CNVs}$, flanked by unique breakpoints [3-5].

The resolution of conventional karyotype analysis is limited to $5 \mathrm{Mb}$ or larger genomic imbalances [6]. The drawback of fluorescence in situ hybridization (FISH) lies in its a targeted approach to detect chromosomal defects, rather than a genome-wide screening method like microarrays or MLPA [7]. Chromosome Microarray Analysis (CMA) is a routine technique in clinical molecular testing nowadays, which contains two types of arrays: oligonucleotide arrays and Single Nucleotide Polymorphism arrays (SNP arrays). Both the arrays 
could detect genome-wide CNVs. Moreover, SNP arrays can detect the mosaicism, triploid, loss of heterozygosity $(\mathrm{LOH})$ and uniparental disomy. In 2010, the American College of Medical Genetics issued practice guidelines for CMA, and pointed out that CMA was recommended as a first-tier test for postnatal patients with multiple congenital anomalies (MCA), intellectual disabilities/developmental delay (ID/DD) and autism spectrum disorders [8]. Recently, CMA has been successfully applied to detect CNVs in patients with CHD, which confirmed the relationship between chromosome microdeletion/microduplication and CHD [9-19].

In this study, we present the results of genome-wide high resolution SNP array analysis in 106 children with CHD in the Chinese cohort, to explore the clinical implication of CMA in genetically etiological diagnosis of CHD.

\section{Methods}

\section{Subjects and sample}

In this study, we collected children diagnosed with CHD with or without MCA or ID/DD and normal karyotype at Guangzhou Women and Children's Medical Center from January 2012 to December 2014. All the children were investigated by the complete cardiac evaluation, echocardiogram, medical history, physical examination, and/or operative reports. Considering patent ductus arteriosus (PDA) was common in children with CHD, the child with PDA was selected only if he/she was born at $>37$ weeks' gestational age and the PDA was unclosed after 6 weeks of life [2]. MCA included cerebral malformation, neural tube and spine defects, craniofacial and neck abnormalities, thorax abnormalities, ventral wall defect, abdomen and gastrointestinal tract defects, genitourinary malformation and skeletal dysplasia. ID/DD was diagnosed by the pediatric specialist. The peripheral blood from these children and their parents were collected. Informed consent was obtained from all the participants. The study was approved by the ethics committees of Guangzhou Women and Children's Medical Center.

According to the National Birth Defects Prevention Study [20, 21], CHD was classified into the following types: septal defect, atrioventricular septal defect (AVSD), conotruncal defects, left ventricular outflow tract obstruction (LVOTO), right ventricular outflow tract obstruction (RVOTO), LVOTO + RVOTO, single ventricle (SV), and PDA (Table 1).

Table 1 Data of pathogenic copy number variants (PCNVs) in children with congenital heart disease (CHD) and CHD classification

\begin{tabular}{|c|c|c|c|c|c|c|c|c|c|}
\hline \multirow[t]{2}{*}{ CHD Classification } & \multicolumn{3}{|c|}{ Simple CHD } & \multicolumn{3}{|c|}{ Associate CHD } & \multicolumn{3}{|l|}{ Total } \\
\hline & No. PCNVs & No. tested & PR (\%) & No. PCNVs & No. tested & PR (\%) & No. PCNVs & No. tested & PR (\%) \\
\hline Septal defect & 9 & 37 & 24.3 & 1 & 6 & 16.8 & 10 & 43 & 23.3 \\
\hline ASD & 5 & 18 & 27.8 & 0 & 0 & 0 & 5 & 18 & 27.8 \\
\hline VSD & 4 & 19 & 21.1 & 0 & 0 & 0 & 4 & 19 & 21.1 \\
\hline$V S D+A S D$ & 0 & 0 & 0 & 1 & 6 & 16.8 & 1 & 6 & 16.8 \\
\hline AVSD & 0 & 1 & 0 & 0 & 2 & 0 & 0 & 3 & 0 \\
\hline Conotruncal defects & 1 & 3 & 33.3 & 1 & 13 & 7.8 & 2 & 16 & 12.5 \\
\hline TOF & 1 & 3 & 33.3 & 1 & 2 & 50 & 2 & 5 & 40 \\
\hline D-TGA & 0 & 0 & 0 & 0 & 11 & 0 & 0 & 11 & 0 \\
\hline LVOTO & 2 & 5 & 40 & 3 & 9 & 33.3 & 5 & 14 & 35.7 \\
\hline $\mathrm{COA}$ & 0 & 2 & 0 & 1 & 4 & 25 & 1 & 6 & 16.7 \\
\hline AS & 2 & 3 & 66.7 & 0 & 1 & 0 & 2 & 4 & 50 \\
\hline IAA, A & 0 & 0 & 0 & 2 & 2 & 100 & 2 & 2 & 100 \\
\hline $\mathrm{COA}+\mathrm{AS}$ & 0 & 0 & 0 & 0 & 2 & 0 & 0 & 2 & 0 \\
\hline RVOTO & 3 & 3 & 100 & 2 & 8 & 25 & 5 & 11 & 45.5 \\
\hline PS/PA & 3 & 3 & 100 & 2 & 8 & 25 & 5 & 11 & 45.5 \\
\hline LVOTO + RVOTO & 0 & 0 & 0 & 3 & 4 & 75 & 3 & 4 & 75 \\
\hline$A S+P S$ & 0 & 0 & 0 & 3 & 4 & 75 & 3 & 4 & 75 \\
\hline Single Ventricle & 0 & 0 & 0 & 0 & 1 & 0 & 0 & 1 & 0 \\
\hline PDA & 4 & 12 & 33.3 & 0 & 0 & 0 & 4 & 12 & 33.3 \\
\hline Total & 19 & 62 & 30.6 & 10 & 43 & 23.2 & 29 & 104 & 27.9 \\
\hline
\end{tabular}

$P R$ positive rate, $A S D$ atrial septal defect, VSD ventricular septal defect, $A V S D$ atrioventricular septal defect, TOF tetralogy of Fallot, $D$-TGA d-transposition of the great arteries, COA coarctation of the aorta, AS aortic stenosis, IAA interruption arterial arch, PS pulmonary stenosis, PA pulmonary atresia, PDA patent ductus arteriosus, LVOTO Left ventricular outflow tract obstruction, RVOTO Right ventricular outflow tract obstruction 
According to the complexity of $\mathrm{CHD}, \mathrm{CHD}$ was divided into two groups: simple CHD and complex CHD [22]. Simple CHD are defined as anatomically discrete (e.g., ventricular septal defect, VSD) or a well-recognized single entity (e.g., tetralogy of Fallot, TOF). Complex $\mathrm{CHD}$ are defined as combinations of different heart defects (single ventricle was included in this group).

According to whether the children with CHD have ID/ DD and/or MCA, CHD was divided into two types: isolated $\mathrm{CHD}$ and syndromic $\mathrm{CHD}$. The syndromic $\mathrm{CHD}$ contained CHD plus MCA, CHD plus ID/DD, and CHD plus MCA and ID/DD.

\section{Chromosome microarray analysis}

CMA was performed using Affymetrix CytoScan HD arrays according to manufacturer's instructions. The procedure included genomic DNA extraction, digestion and ligation, PCR amplification, PCR product purification, quantification and fragmentation, labeling, array hybridization, washing and scanning. Data was analyzed with Chromosome Analysis Suite software version 1.2 (Affymetrix). The reporting threshold was set at $100 \mathrm{~kb}$ with marker count $\geq 50$. CNVs were interpreted as benign listed in Database of Genomic Variants (DGV) database $(n>3$ studies or documented in $>1 \%$ of the normal population) or no gene included (not close to known CHD genes within $1 \mathrm{Mb}$ ) [23]. CNVs was classified as pathogenic copy number variations (PCNVs) if these CNVs overlapped completely with the minimal critical region of a wellknown microdeletion or microduplication syndrome, or if the CNV comprised a dosage-sensitive gene known to cause a similar phenotype, referring to ClinGen Dosage Sensitivity Map (http://www.ncbi.nlm.nih.gov/projects/ dbvar/clingen/). Rare CNVs $(<1 \%$ in normal population and without OMIM genes) that do not meet the criteria above, should be considered as variant of uncertain clinical significance (VOUS), until proven otherwise (e.g. by functional studies) $[8,23]$. For interpretation of these results, our in-house database and the following public database were used: DGV (http://projects.tcag.ca/variation/), Cytogenomics Array Group CNV Database (https:// www.cagdb.org), Database of Chromosomal Imbalance and Phenotype in Humans using Ensembl Resources database (DECIPHER, http://decipher.sanger.ac.uk/), Online Mendelian Inheritance in Man (OMIM, http://www.omim.org), University of California Santa Cruz (UCSC, http://genome.ucsc.edu/, hg19), ClinVar (http:// www.clinvar.com/) and CHD wiki (http://homes.esat.kuleuven.be/ bioiuser/chdwiki/index.php/Main_Page).

All CNVs were further confirmed by Real-Time Polymerase Chain Reaction. Parental analysis were performed to interpret VOUS.

\section{Statistical analysis}

Statistical analyses were performed using the Statistic Package for Social Science (SPSS) 13.0 statistical software package (SPSS Inc.). The PCNVs detection rates in children with simple $\mathrm{CHD}$ and complex $\mathrm{CHD}$ were compared using chi square test. Frequencies of recurrent $\mathrm{CNVs}$ in this study and the control cohorts were compared using fisher's exact test. $P$ value $<0.05$ was statistically significant. The PCNVs detection rates in isolated CHD, CHD plus MCA, CHD plus ID/DD, and CHD plus MCA and ID/DD were pairwise compared using chi square test or fisher's exact test, $p$ value $<0.008$ was statistically significant.

\section{Results}

CMA was performed in 104 children (67 males and 37 females) with CHD aged from 5 days to 8 years old. CNVs were identified in $96.2 \%(100 / 104)$ of the children. The size of CNVs ranged from $102 \mathrm{~kb}$ to $13.8 \mathrm{Mb}$. CNVs were interpreted as benign or likely benign in $69.2 \%$ (72/ 104) children. The detection rate for PCNVs was $27.9 \%$ $(29 / 104)$, and the VOUS rate was $2.9 \%$ (3/104) after parental analysis.

Detailed CHD classification and demographic data of the children were listed in Table 1 . The percentages of children with simple CHD and complex CHD were 58.7\% (61/104) and $41.3 \%(43 / 104)$, respectively. PCNVs were identified in $31.1 \%(19 / 61)$ children with simple CHD and in 23.2\% (10/ 43) children with complex CHD. Pearson Chi-square test showed that there was no significant difference between these two groups $(P>0.05)$. PCNVs were detected in $23.3 \%$ (10/43) of septal defect, $0(0 / 3)$ of AVSD, 12.5\% (2/16) of conotruncal defects, 35.7\% (5/14) of LVOTO, 45.5\% (5/11) of RVOTO, 75\% (3/4) of LVOTO + RVOTO, 0 (0/1) of SV, and $33.3 \%(4 / 12)$ of PDA.

The detection rates of PCNVs in isolated CHD and syndromic CHD were $17.9 \%$ (7/39) and 33.8\% (22/65), respectively. There was no significant difference between these two groups $(P>0.05)$. The detection rates for PCNVs were 20\% (5/25) in CHD plus MCA, 63.2\% (12/ $19)$ in CHD plus ID/DD, and $23.8 \%(5 / 21)$ in CHD plus MCA and ID/DD, respectively (Table 2). The PCNVs rate of CHD plus ID/DD was significantly higher than that of isolated CHD (63.2 vs $17.9 \%, P=0.001)$ and CHD plus MCA (63.2 vs $20 \%, P=0.004)$.

PCNVs were identified in 29 children (Table 3, including 22q11 deletion syndrome $(n=6), 22 \mathrm{q} 11$ duplication syndrome $(n=1)$, Williams-Beuren syndrome $(n=6)$, Angleman/Prader-Willi syndrome $(n=1)$, WolfHirschhorn syndrome $(n=2)$, Schinzel-Giedion midface retraction syndrome $(n=1), 15 \mathrm{q} 24$ recurrent microdeletion syndrome $(n=1), 1 \mathrm{p} 36$ microdeletion syndrome $(n=1)$, Cornelia de Lange syndrome $4(n=1)$, Marfan syndrome $(n=1)$, Opitz G/BBB syndrome $(n=1), 6 \mathrm{q} 24$ 
Table 2 Classification of children with CHD and/or other diagnoses (MCA, ID/DD)

\begin{tabular}{|c|c|c|c|c|c|c|c|c|c|}
\hline \multirow{2}{*}{$\begin{array}{l}\text { Classification of } \\
\text { symptoms }\end{array}$} & \multicolumn{3}{|l|}{ Simple CHD } & \multicolumn{3}{|c|}{ Complex CHD } & \multicolumn{3}{|l|}{ Total } \\
\hline & No. pCNVs & No. tested & PR (\%) & No. pCNVs & No. tested & PR (\%) & No. pCNVs & No. tested & PR (\%) \\
\hline Isolated CHD & 3 & 15 & 20.0 & 4 & 24 & 16.7 & 7 & 39 & 17.9 \\
\hline Syndromic CHD & 16 & 46 & 34.8 & 6 & 19 & 31.6 & 22 & 65 & 33.8 \\
\hline$C H D+M C A$ & 4 & 18 & 22.2 & 1 & 7 & 14.3 & 5 & 25 & 20 \\
\hline $\mathrm{CHD}+\mathrm{ID} / \mathrm{DD}$ & 8 & 13 & 61.5 & 4 & 6 & 66.7 & 12 & 19 & 63.2 \\
\hline $\mathrm{CHD}+\mathrm{MCA}+\mathrm{ID} / \mathrm{DD}$ & 4 & 15 & 26.7 & 1 & 6 & 16.7 & 5 & 21 & 23.8 \\
\hline Total & 19 & 61 & 31.1 & 10 & 43 & 23.2 & 29 & 104 & 27.9 \\
\hline
\end{tabular}

$P R$ positive rate, $M C A$ multiple congenital anomalies, ID/DD intellectual disabilities/development delay

LOH $(n=1)$, and CNVs overlapped with DECIPHER patient entries $(n=6)$.

In this study, PCNVs in $79.3 \%(23 / 29)$ of the children contained genes contributing to $\mathrm{CHD}$ (Table 3 ). The genes responsible for syndromic CHD included TBX1 (22q11 deletion syndrome), ELN (Williams-Beuren syndrome), $E V C 2$ and EVC (Wolf-Hirschhorn syndrome), STRA6 (15q24 recurrent microdeletion syndrome), FBN1 (Marfan syndrome), MID1 (Opitz G/BBB syndrome), RAD21 (Cornelia de Lange syndrome 4) and SETBP1 (SchinzelGiedion midface retraction). In addition, the genes contributing to non-syndromic CHD included CRELD1, RAF1 and CITED2. DVL1 and SKI were identified as candidate genes for CHD in the current study.

CNVs detected in 9 children were classified as VOUS initially, further parental microarray analysis showed that CNVs in 6 children were inherited. The remaining CNVs in the other 3 children (Table 3, child 30-32) were de novo and the clinical significance was still unknown. Therefore, the VOUS rate was $2.8 \%$ in this study. The three VOUS were 11p15.4 duplication (chr11:3,923,985-4,242,111, $180 \mathrm{~kb}$ ), 10q21.3 duplication (chr10:69,026,332-69,430,434, $400 \mathrm{~kb}$ ) and 6q22.31 duplication (chr6:118,693,553119,050,523, $360 \mathrm{~kb})$. Three genes, STIM1, CTNNA3 and $P L N$ relevant with $\mathrm{CHD}$, located in these fragments respectively. For the other children with benign or pathogenic CNVs, their parents rejected further parental analysis by CMA.

\section{Discussion}

In the past few years, several studies have investigated postnatal cases with syndromic CHD by array CGH (aCGH) (Table 4) $[9,11,13,14,16-19]$. Different arrays were used in these studies, and the PCNVs detection rate ranged from 10.9 to $25.5 \%$. Bachman's study showed that the lowest PCNVs detection rate was 10.9\% (5/46) using Roche NimbleGen $135 \mathrm{~K}$ arrays [18]. The highest detection rate was $25.5 \%(5 / 20)$ by Agilent $244 \mathrm{~K}$ array from Syrmou's study [19]. In our study, the total detection rate for PCNVs reached 27.9\% (29/104) by CytoScan HD array, including 1,950,000 oligonucleotide probes and 750,000 SNP probes. Our results demonstrated further that denser arrays with high resolution will lead to a proportional increase in number of PCNVs [13, 24].

CMA has also been applied in children with isolated CHD previously $[10-12,15]$. The PCNVs detection rates ranged from 0 to $5.3 \%$ (Table 4). Richards et al. studied 20 children with isolated CHD and 20 children with CHD plus MCA, the results showed that PCNVs detection rate in isolated $\mathrm{CHD}$ was 0 and that in CHD plus MCA was $25 \%$, and the highest PCNVs detection rate was $45 \%$ in children with CHD plus neurologic defects [11]. Therefore, CMA was not recommended by Richards for children with isolated CHD. In our study, PCNVs detection rate was $17.9 \%$ (7/39) in isolated CHD. The PCNVs detection rates for CHD plus MCA, CHD plus ID/DD and CHD plus MCA and ID/DD were 20, 63.2 and $23.8 \%$, respectively. PCNVs detection rate in CHD plus ID/DD was significantly higher than that of isolated CHD $(P=0.001)$ and $\mathrm{CHD}$ plus MCA $(P=0.004)$. Our data demonstrated that CMA is the most useful for genetic diagnosis in children with CHD plus ID/DD. In addition, we also recommended CMA investigation for children with isolated CHD.

In this study, PCNVs were detected in $31.1 \%(19 / 61)$ children with simple CHD and 23.2\% (10/43) children with complex CHD by CMA. There was no significant difference between the two groups $(P>0.05)$. Detection rates in various types of CHD were different. Shaffer et al. reviewed 580 fetuses with $\mathrm{CHD}$ and normal karyotype by aCGH [25], and revealed the detection rates of PCNVs as follows: $16.2 \%(11 / 68)$ in LVOTO, $11.6 \%$ (5/ 43) in conotruncal defect and $10.6 \%(14 / 132)$ in septal defect. The above three types of CHD in fetuses were the most frequent. In our study, the PCNVs detection rates in different types of CHD in isolated or with additional anomalies were as follows in turn: $75 \%(3 / 4)$ in LVOTO + RVOTO, 45.5\% (5/11) in RVOTO, 35.7\% (5/ 14) in LVOTO, $33.3 \%(4 / 12)$ in PDA, $23.3 \%(10 / 43)$ in septal defect, $12.5 \%(2 / 16)$ in conotruncal defects. Our data demonstrate that LVOTO and/or RVOTO were most probably related to microdeletion/microduplication. Of the 29 children with PCNVs, 22 (75.9\%) were complicated with MCA and/or DD/ID. High detection 
Table 3 Pathogenic copy number variants and variants of unknown significance detected by Chromosome Microarray Analysis in children with CHD

\begin{tabular}{|c|c|c|c|c|c|c|}
\hline \multirow[t]{2}{*}{ Child } & \multirow[t]{2}{*}{$\mathrm{Age}^{\mathrm{a}}$} & \multicolumn{2}{|l|}{ Phenotype } & \multirow[t]{2}{*}{ CNVs: Region and size } & \multirow{2}{*}{$\begin{array}{l}\text { Known syndrome/Decipher } \\
\text { number/OMIM number }\end{array}$} & \multirow{2}{*}{$\begin{array}{l}\text { Significant gen } \\
\text { fonts) /candida } \\
\text { relating to } \mathrm{CHL}\end{array}$} \\
\hline & & Cardiac diagnosis & MCA or ID/DD & & & \\
\hline \multicolumn{7}{|c|}{ Pathogenic CNVs } \\
\hline \multirow[t]{2}{*}{1} & \multirow[t]{2}{*}{$8 y$} & \multirow[t]{2}{*}{ ASD } & \multirow[t]{2}{*}{ ID } & Dup 11q24.2-q25 (8.5 Mb) & Decipher number 255590 & None \\
\hline & & & & Del 1q43-q44 (6.2 Mb) & Decipher number 284767 & None \\
\hline 2 & $7 \mathrm{~m}$ & $P S+A S D$ & None & Del 22q11.21 (3.2 Mb) & 22q11 deletion syndrome & $T B X 1$ \\
\hline \multirow[t]{3}{*}{3} & \multirow[t]{3}{*}{$10 \mathrm{~m}$} & \multirow[t]{3}{*}{ PDA } & \multirow{3}{*}{$\begin{array}{l}\text { Congenital anal } \\
\text { atresia + DD }\end{array}$} & Dup 3p26.1-p24.3 (13.8 Mb) & Decipher number 260758 & CRELD1; RAF1 \\
\hline & & & & Del 6q13-q14.1 (5.2 Mb) & Decipher number 249539 & None \\
\hline & & & & Dup 17q12 (1.4 Mb) & Decipher number 278456 & None \\
\hline 4 & $4 y$ & PDA & Leukodystrophy & Del 1p36.33-p36.31(4.8 Mb) & 1p36 microdeletion syndrome & DVL1;SKI \\
\hline 5 & $13 \mathrm{~m}$ & ASD & $\mathrm{DD}$ & Del 15q24.1-q24.2 (3.1 Mb) & $\begin{array}{l}15 q 24 \text { recurrent microdeletion } \\
\text { syndrome }\end{array}$ & STRAG \\
\hline 6 & $5 y$ & PS & ID & Del 15q11.2-q13.1 (4.9 Mb) & $\begin{array}{l}\text { Angelman/Prader-Willi } \\
\text { syndrome }\end{array}$ & None \\
\hline 7 & $5 \mathrm{~m}$ & VSD & $\mathrm{DD}$ & Del 4p16.3-p16.2 (5.7 Mb) & Wolf-Hirschhorn syndrome & $E V C 2 ; E V C$ \\
\hline 8 & $2 \mathrm{~m}$ & ASD & $\begin{array}{l}\text { Laryngeal cartilage } \\
\text { dysplasia }\end{array}$ & Del 22q11.21 (2.4 Mb) & 22q11 deletion syndrome & $T B X 1$ \\
\hline 9 & $2 y$ & VSD & $\mathrm{ID}$ & Del 22q11.21 (3.2 Mb) & 22q11 deletion syndrome & $T B X 1$ \\
\hline 10 & $14 \mathrm{~m}$ & ASD & None & Del 22q11.21 (1.4 Mb) & 22q11 deletion syndrome & $T B X 1$ \\
\hline 11 & $2 y$ & ASD & Cleft palate + ID & Dup 18q12.3 (0.64 Mb) & $\begin{array}{l}\text { Schinzel-Giedion midface } \\
\text { retraction syndrome }\end{array}$ & SETBP1 \\
\hline 12 & $2 y$ & $A S+P S$ & $\mathrm{DD}$ & Del 7q11.23 (1.4 Mb) & Williams-Beuren syndrome & ELN \\
\hline 13 & $3 y$ & $\begin{array}{l}\text { TOF + PLSVC + } \\
\text { Pericardial defect }\end{array}$ & $\begin{array}{l}\text { Diaphragmatic } \\
\text { hernia + ID }\end{array}$ & Dup 2q12.3 (0.42 Mb) & Decipher number 287980 & None \\
\hline 14 & $1 \mathrm{~m}$ & $I A A, A+V S D$ & $\begin{array}{l}\text { fingers of both hands } \\
\text { and left toe deformity }\end{array}$ & Dup Xp22.2 (0.72 Mb) & Opitz G/BBB syndrome & MID1 \\
\hline 15 & $1 y$ & $P S+V S D$ & $\mathrm{ID}$ & Del 22q11.21 (3.2 Mb) & 22q11 deletion syndrome & $T B X 1$ \\
\hline \multirow[t]{2}{*}{16} & \multirow[t]{2}{*}{$15 \mathrm{~m}$} & \multirow[t]{2}{*}{ PDA } & \multirow[t]{2}{*}{$\mathrm{DD}$} & Del 1p36.33 (0.35 Mb) & Decipher number 106 & None \\
\hline & & & & Dup 17q25.1-q25.3 (6.4 Mb) & Decipher number 249584 & None \\
\hline 17 & $18 \mathrm{~m}$ & ASD & Cleft palate + DD & Del 4p16.3-p16.1 (7.6 Mb) & Wolf-Hirschhorn Syndrome & EVC2; EVC \\
\hline 18 & $11 d$ & $I A A, A+V S D$ & None & Del 7q11.23 (1.4 Mb) & Williams-Beuren syndrome & ELN \\
\hline 19 & $8 \mathrm{~m}$ & $A S+P S$ & $\mathrm{DD}$ & Del 7q11.23 (1.4 Mb) & Williams-Beuren syndrome & $E L N$ \\
\hline 20 & $2 y$ & PS & None & Dup 15q21.1 (1.58 Mb) & Marfan syndrome & FBN1 \\
\hline \multirow[t]{2}{*}{21} & \multirow[t]{2}{*}{$3 y$} & \multirow[t]{2}{*}{ TOF } & \multirow{2}{*}{$\begin{array}{l}\text { Absence of corpus } \\
\text { callosum + cerebellar } \\
\text { vermis hypoplasia + ID }\end{array}$} & Del 1q43-q44 (7.6 Mb) & Decipher number 249647 & None \\
\hline & & & & Dup 10p15.3-p14 (6.7 Mb) & Decipher number 278831 & None \\
\hline 22 & $3 y$ & $C O A+V S D+A S D$ & ID & LOH 6q24.1-q24.2 (5.2 Mb) & Decipher number 290225 & CITED2 \\
\hline \multirow[t]{2}{*}{23} & \multirow[t]{2}{*}{$1 \mathrm{~m}$} & \multirow[t]{2}{*}{ AS } & Hemivertebra + Adduction & Del 8q23.3-q24.11(1.24 Mb) & Cornelia de Lange syndrome 4 & RAD21 \\
\hline & & & $\begin{array}{l}\text { deformity of thumb + } \\
\text { Polydactyly + Funnel chest }\end{array}$ & Dup 11p15.3-15.2 (0.75 Mb) & None & None \\
\hline 24 & $2 y$ & VSD & ID & Del 22q11.21 (3.2 Mb) & 22q11 deletion syndrome & $T B X 1$ \\
\hline 25 & $2 y$ & PS & $\mathrm{ID}$ & Del 7q11.23 (1.5 Mb) & Williams-Beuren syndrome & $E L N$ \\
\hline 26 & $2 \mathrm{~m}$ & AS & None & Del 7q11.23 (1.5 Mb) & Williams-Beuren syndrome & $E L N$ \\
\hline 27 & $2 \mathrm{~m}$ & $A S+P S$ & None & Del 7q11.23 (1.4 Mb) & Williams-Beuren syndrome & $E L N$ \\
\hline 28 & $7 \mathrm{~m}$ & PDA & Cleft palate & Dup 22q11.21 (2.5 Mb) & 22q11 duplication syndrome & $T B X 1$ \\
\hline 29 & $6 \mathrm{~m}$ & $A S D+V S D$ & None & Dup 17q25.1-q25.3 (8.5 Mb) & Decipher number 254723 & None \\
\hline & & & & Del 20q13.33 (1.3 Mb) & Decipher number 2615 & None \\
\hline
\end{tabular}


Table 3 Pathogenic copy number variants and variants of unknown significance detected by Chromosome Microarray Analysis in children with CHD (Continued)

\begin{tabular}{|c|c|c|c|c|c|c|}
\hline \multicolumn{7}{|c|}{ Variants of unknown significance } \\
\hline \multicolumn{7}{|c|}{$\begin{array}{lll}301 \mathrm{~m} \quad \begin{array}{l}\text { CoA }+ \text { Heart } \\
\text { Enlargement }\end{array} \quad \text { None }\end{array}$} \\
\hline 31 & $1 \mathrm{~m}$ & $A S+V S D$ & None & Dup 10q21.3 (0.4 Mb) & None & CTNNA3 \\
\hline 32 & $1 \mathrm{~m}$ & $\begin{array}{l}\text { D-TGA + VSD } \\
+A S D\end{array}$ & None & Dup 6q22.31 (0.36 Mb) & None & PLN \\
\hline
\end{tabular}

ASD atrial septal defect, PDA patent ductus arterious, PS pulmonary stenosis, VSD ventricular septal defect, TOF tetralogy of Fallot, $P L S V C$ persistent left superior vena cava, $A S$ aortic stenosis, IAA,A interruption arterial arch, A type, COA coarctation of the aorta, $D$-TGA d-transposition of the great arteries, DD development delay, ID intellectual disabilities

${ }^{a}$ Age column: $y$, years; $m$, months; $d$, days

${ }^{b}$ Accordion to CHD wiki (http://homes.esat.kuleuven.be/ bioiuser/chdwiki/index.php/Main_Page)and OMIM database (http://www.omim.org)

rate in children with PDA (33.3\%) was obtained in this study, and we noticed that all the 12 children with PDA were complicated with MCA and/or ID/DD. There was no PCNVs detected in children with $\operatorname{AVSD}(n=2)$ and SV $(n=1)$, this may be due to the small sample size in our study.

Gijsbers et al. suggested that as the rising of aCGH resolution, there will be more VOUS identified [26]. In the previous studies in children with $\mathrm{CHD}$ by microarray, the VOUS detection rates ranged from 3.4 to $11.7 \%[9,11,16]$. In this study, CNVs detected in 9 children were unknown of clinical significance. After parental microarray analysis, $\mathrm{CNVs}$ in 6 children were inherited, the remaining CNVs in the other 3 children (Table 3, child 30-32) were de novo and the clinical significance was still unknown. Finally, the VOUS rate was $2.9 \%$ in our study, which did not increase obviously as the resolution rise compared with previous studies. Therefore, parental analysis could assist in interpreting $\mathrm{CNVs}$ and reducing VOUS rate.

The clinical features of $1 \mathrm{p} 36$ microdeletion syndrome include microcephaly, brachycephaly, developmental delay with hypotonia, seizures and cardiac defects [27]. In our study, CMA revealed a $4.8 \mathrm{Mb}$ deletion at 1p36.33-p36.31 (chr1:849,466-5,685,789) in child 4 with PDA and leukodystrophy, which contained the SKI and DVL1 genes. SKI morphant embryos showed severe cardiac anomalies, especial complete failure in cardiac looping and malformations of the outflow tract [28]. Researchers have studied $D V L 1$ null mice and reported that DVL1-mediated planar cell polarity signal was crucially for cardiac outflow tract development [29]. Based on the above data, SKI and DVL1 could be the main genes responsible for CHD phenotypes in 1p36 deletion syndrome.

A $4.9 \mathrm{Mb}$ deletion at 15q11.2-q13.1 (chr15: $23,620,191-28,540,345$ ) was detected in child 6 (Table 3) with pulmonary stenosis plus ID. He was diagnosed as Angelman/Prader-Willi syndrome, the clinical features include ID, microcephaly, seizures, truncal ataxia, feeding difficulties in infancy and muscular hypotonia. Soemedi et al. first reported the association of $15 \mathrm{q} 11.2$ deletion with CHD, in their study the phenotypes contained left-side malformations, coarctation of the aorta, septal defect and TOF [30]. Geng et al. have detected

Table 4 The comparison of studies in postnatal patients with isolate/syndromic CHD

\begin{tabular}{|c|c|c|c|c|c|}
\hline Study & Array type & No. tested & Other diagnosis & PCNVs rates & VOUS rates \\
\hline Thienpont et al. 2007 [9] & $1 \mathrm{Mb} \mathrm{BAC}$ & 60 & MCA, ID & $16.7 \%$ & $11.7 \%$ \\
\hline \multirow[t]{2}{*}{ Richards et al. 2008 [11] } & \multirow[t]{2}{*}{$385 \mathrm{~K}$ oligo arrays } & 20 & $\mathrm{MCA}, \mathrm{DD} / \mathrm{ID}$ & $25 \%$ & \multirow[t]{2}{*}{$9.8 \%$} \\
\hline & & 20 & None & 0 & \\
\hline Erdogan et al. 2008 [10] & $1 \mathrm{Mb}$ BAC or $1 \times 244 \mathrm{~K}$ Agilent arrays & 105 & None & $4.7 \%$ & Unknow \\
\hline Greenway et al. 2009 [12] & Affymetrix SNP 6.0 & 114 & None & $5.3 \%$ & Unknow \\
\hline Breckpot J et al. 2010 [13] & $1 \mathrm{Mb}$ array & 150 & MCA & $17.3 \%$ & Unknow \\
\hline Rauch et al. 2010 [14] & $100 \mathrm{~K}$ Affymetrix & 19 & MCA & $21 \%$ & Unknow \\
\hline Goldmuntz et al. 2011 [16] & 100 K Oligo array & 58 & MCA & $20.7 \%$ & $3.4 \%$ \\
\hline Breckpot et al. 2011 [15] & Affymetrix SNP 6.0 & 46 & None & $4.3 \%$ & Unknow \\
\hline Derwinska et al. 2012 [17] & 180 K Oligo & 150 & MCA & $14 \%$ & Unknow \\
\hline Syrmou et al. 2013 [19] & $1 \times 244 \mathrm{~K}$ or $4 \times 180 \mathrm{~K}$ Agilent arrays & 55 & MCA & $25.5 \%$ & Unknow \\
\hline Bachman et al. 2013 [18] & Roche NimbleGen $135 \mathrm{~K}$ arrays & 46 & MCA & $10.9 \%$ & Unknow \\
\hline Our study & Affymetrix CytoScan HD arrays & 104 & MCA, ID/DD & $27.9 \%$ & $2.9 \%$ \\
\hline
\end{tabular}

BAC bacterial artificial chromosome, MCA multiple congenital anomalies, DD/ID development delay/intellectual disabilities, SNP single nucleotide polymorphism 
four patients with 15q11.2 deletion (size range 245$2703 \mathrm{~kb}$ ) in $502 \mathrm{CHD}$ patients, their result also showed the $15 \mathrm{q} 11.2$ deletion has low penetrance in CHD patients [31]. These data indicated that $15 \mathrm{q} 11.2$ deletion, containing the Angelman/Prader-Willi syndrome region, represents a critical CHD locus. However, further studies are need to ascertain the genes responsible for CHD.

In the present study, we identified two children with 1q43-q44 deletion. Child 1 manifested atrial septal defect (ASD) and ID. Child 21 manifested TOF and absence of corpus callosum. Our study showed significantly higher frequency of 1q43-q44 deletion (2/104) than that of the 9170 control cases $(4 / 9170)(P=0.002)[30,32]$. Therefore, 1q43-q44 should be considered as a locus associated with cardiac development. The clinical features of 1q43-44 deletion syndrome include ID, language retardation, characteristic facial features, abnormalities of the corpus callosum and seizures [33]. Summarizing the literature, patients with 1q43-q44 deletion manifesting ID/DD or structural anomaly of central nervous system $(69 / 83,83.1 \%)$ more frequently than CHD $(19 / 76,25 \%)(P<0.001$, Table 5$)$. These data suggested 1q43-q44 deletion may have low penetrance in CHD children.

The child 11, a girl with ASD and cleft palate which had been corrected surgically. She was diagnosed with mental retardation at 2 years old by pediatric doctor. CMA test revealed chromosome 18q12.3 duplication (chr18: $41,814,626-42,453,303)$. SETBP1 gene located in the fragment which was responsible for Schinzel-Giedion midface retraction syndrome, and point mutation is the most common type. The clinical features included severe mental retardation, distinctive facial features, and multiple congenital malformations such as skeletal abnormalities and cardiac defects. A dominant-negative or gain-of-function mechanism was proposed to underlie this syndrome [34]. We sequenced the 5 exons of SETBP1 gene, and no mutation was detected. The SETBP1 gene duplication was in accordance with gain-of-function mechanism, and the child's manifestations were similar with the phenotypes of Schinzel-Giedion midface retraction syndrome, Therefore, SETBP1 should be the main responsible gene for this patient.

The child 22 had coarctation of aorta, VSD, ASD (cardiac surgery was performed when he was 1 month old) and ID. Brain MRI showed normal result. CMA test revealed a $5.2 \mathrm{Mb} \mathrm{LOH}$ on chromosome $6 \mathrm{q} 24.1$ q24.2 (chr6:139,184,381-144,411,648). This LOH fragment included PLAG1 and HYMAI genes, which were associated with imprinting disorder intrauterine growth retardation and neonatal hyperglycemia [35]. Another gene CITED2 also located in the $\mathrm{LOH}$, which has been identified associated with cardiac malformations, including atrial and ventricular septal defects, overriding aorta, double-outlet right ventricle and right-side aortic arches [36]. Therefore, this fragment was classified as PCNVs.

Of the 29 children with PCNVs, 7 (24.1\%) were with $22 \mathrm{q} 11$ deletion $(n=6)$ or duplication $(n=1)$ syndrome, which was the most common type. The incidence of 22q11 deletion/duplication was $6.7 \%$ (7/ 104) in the children with CHD in the present study. These data indicate that in addition to CMA it could be more cost-effective to exclude $22 \mathrm{q} 11$ deletion/duplication firstly by targeted technique such as MLPA in children with CHD.

In the 3 children with VOUS, we identified CHD candidate genes such as STIM1, CTNNA3 and PLN. STIM1 gene mutation could cause cardiomyocyte hypertrophy [37]. PLN gene mutation was associated with cardiomyopathy [38]. CTNNA3 gene mutation could cause arrhythmogenic right ventricular dysplasia, compound heterozygous deletion was related to ASD [39, 40]. However, the children's symptoms in this study were inconsistency with genotypes in the database. Further study of these genes are still needed to evaluate the clinical implication.

\section{Conclusion}

CMA has been recommended as a first-tier clinical diagnosis test in patients with DD, ID and/or MCA $[8,41]$. Study from Bachman also recommended aCGH as a first-tier test in evaluation of neonates with CHD [18]. In the present study, we obtained the highest detection rate in children with CHD plus ID/ DD (63.2\%), while in children with isolated CHD we still obtained relatively high detection rate (17.9\%). Based on the above data, we suggest CMA as a firsttier test in children with CHD, especially in children with CHD plus ID/DD.

Table 5 1q43-q44 deletion in our study compared with other studies

\begin{tabular}{|c|c|c|c|c|c|c|}
\hline Phenotype & Our case & $1 \mathrm{q} 43$ deletion $^{\mathrm{a}}$ & $1 \mathrm{q} 44$ deletion $^{\mathrm{b}}$ & 1q43-q44 deletion ${ }^{c}$ & 1q42-q44 deletion ${ }^{d}$ & $\overline{\text { Total }}$ \\
\hline ID/DD or CNS abnormal & $2 / 2$ & $22 / 27$ & $24 / 24$ & $15 / 24$ & $6 / 6$ & $69 / 83$ \\
\hline Congenital heart defects & $2 / 2$ & $8 / 24$ & $5 / 22$ & $2 / 24$ & $2 / 4$ & $19 / 76$ \\
\hline
\end{tabular}

ID/DD intellectual disabilities/development delay, CNS central nervous system

${ }^{\text {a }}$ Reference to [42-45]

${ }^{\text {b Reference to }[42-44,46-48]}$

'Reference to $[33,49]$

dReference to [44] 


\section{Abbreviations}

aCGH: Array CGH; AOH: Absence of heterozygosity; ASD: Atrial septal defect; AVSD: Atrioventricular septal defect; CHD: Congenital heart disease; CITED2: Cbp/p300-interacting transactivator, with Glu/Asp-rich carboxyterminal domain, 2; CMA: Chromosome microarray analysis; CNVs: Copy number variations; CRELD1: Cysteine-rich with EGF-like domains 1; CTNNA3: Catenin (cadherin-associated protein), alpha 3; CYFIP1: Cytoplasmic FMR1 interacting protein 1; DD: Developmental delay; DECIPHER: Database of chromosomal imbalance and phenotype in humans using ensembl resources; DGV: Database of genomic variants; DVL1: Dishevelled segment polarity protein 1; ELN: Elastin; EVC: Ellis van Creveld syndrome; EVC2: Ellis van Creveld syndrome 2; FBN1: Fibrillin 1; HYMAl: Hydatidiform mole associated and imprinted (non-protein coding); ID: Intellectual disabilities; LVOTO: Left ventricular outflow tract obstruction; MCA: Multiple congenital anomalies; MID1: Midline 1; NIPA1: Non imprinted in Prader-Willi/Angelman syndrome 1: NIPA2: Mon imprinted in Prader-Willi/Angelman syndrome 2; OMIM: Online mendelian inheritance in man; PCNVs: Pathogenic copy number variations; PDA: Patent ductus arteriosus; PLAG1: Pleiomorphic adenoma gene 1; PLN: Phospholamban; RAD21: RAD21 homolog; RAF1: Raf-1 proto-oncogene, serine/threonine kinase; RVOTO: Right ventricular outflow tract obstruction; SETBP1: SET binding protein 1; SKI: SKI proto-oncogene; STIM1: Stromal interaction molecule 1; STRA6: Stimulated by retinoic acid 6; SV: Single ventricle; TBX1: T-box 1; TTN: Titin; TUBGCP5: Tubulin, gamma complex associated protein 5; UCSC: University of California Santa Cruz; VOUS: Variant of uncertain clinical significance; VSD: Ventricular septal defect

\section{Acknowledgments}

We thank all the children and their family members for their interest and cooperation.

\section{Funding}

This study was supported by Science and technology project of Guangdong Province (2014A020213015), the key project of Guangzhou Science and Information Technology Bureau (201300000086), the key project of Guangzhou Health Bureau (201102A212026) and Medical research foundation of Guangdong Province (A2013515).

\section{Availability of data and materials}

The datasets used and/or analysed during the current study available from the corresponding author on reasonable request.

\section{Authors' contributions}

XL Wu contributed to the implementation of the study, analysis and writing of this manuscript. R Li supervised the development of the manuscript and contributed to the analysis and writing. F Fu, M Pan, J H and X Yang interviewed the participants and collected and collated the data. YL Zhang and FT Li contributed to the experiment and data analysis. C Liao contributed to the study design, initiated the study, and provided comments on the manuscript. All authors read and approved the final manuscript.

\section{Competing interests}

The authors declare that they have no competing interests.

\section{Consent for publication}

Not applicable. Written consents for the publication of the absolute ages have been given by the parents of the children.

\section{Ethics approval and consent to participate}

The study was approved by the ethics committees of Guangzhou Women and Children's Medical Center, and written informed consents to participate and the obtainment of blood samples were given on behalf of the children by the parents. Written informed consents to participate were also given by the parents for their own participation in the study, including blood collection.

\section{Publisher's Note}

Springer Nature remains neutral with regard to jurisdictional claims in published maps and institutional affiliations.
Received: 18 February 2016 Accepted: 11 April 2017

Published online: 04 May 2017

\section{References}

1. van der Linde D, Konings EE, Slager MA, Witsenburg M, Helbing WA, Takkenberg JJ, et al. Birth prevalence of congenital heart disease worldwide: a systematic review and meta-analysis. J Am Coll Cardiol. 2011;58(21):2241-7.

2. Hartman RJ, Rasmussen SA, Botto LD, Riehle-Colarusso T, Martin CL, Cragan JD, et al. The contribution of chromosomal abnormalities to congenital heart defects: a population-based study. Pediatr Cardiol. 2011;32(8):1147-57.

3. Lindsay EA, Vitelli F, Su H, Morishima M, Huynh T, Pramparo T, et al. Tbx1 haploinsufficiency in the DiGeorge syndrome region causes aortic arch defects in mice. Nature. 2001;410(6824):97-101.

4. Yagi H, Furutani Y, Hamada H, Sasaki T, Asakawa S, Minoshima S, et al. Role of TBX1 in human del22q11.2 syndrome. Lancet. 2003:362(9393):1366-73.

5. Pober BR. Williams-Beuren syndrome. N Engl J Med. 2010;362(3):239-52.

6. ACOG Committee Opinion No. 446: array comparative genomic hybridization in prenatal diagnosis. Obstet Gynecol. 2009; 114(5): 1161-1163.

7. Pergament E. New molecular techniques for chromosome analysis. Baillieres Best Pract Res Clin Obstet Gynaecol. 2000;14(4):677-90.

8. Manning M, Hudgins L, Professional P, Guidelines C. Array-based technology and recommendations for utilization in medical genetics practice for detection of chromosomal abnormalities. Genet Med. 2010;12(11):742-5.

9. Thienpont B, Mertens L, de Ravel T, Eyskens B, Boshoff D, Maas N, et al. Submicroscopic chromosomal imbalances detected by array-CGH are a frequent cause of congenital heart defects in selected patients. Eur Heart J. 2007;28(22):2778-84

10. Erdogan F, Larsen LA, Zhang L, Tumer Z, Tommerup N, Chen W, et al. High frequency of submicroscopic genomic aberrations detected by tiling path array comparative genome hybridisation in patients with isolated congenital heart disease. J Med Genet. 2008;45(11):704-9.

11. Richards AA, Santos $L$, Nichols HA, Crider BP, Elder FF, Hauser NS, et al. Cryptic chromosomal abnormalities identified in children with congenital heart disease. Pediatr Res. 2008;64(4):358-63.

12. Greenway SC, Pereira AC, Lin JC, DePalma SR, Israel SJ, Mesquita SM, et al. De novo copy number variants identify new genes and loci in isolated sporadic tetralogy of Fallot. Nat Genet. 2009;41(8):931-5.

13. Breckpot J, Thienpont B, Peeters $H$, de Ravel $T$, Singer A, Rayyan M, et al. Array comparative genomic hybridization as a diagnostic tool for syndromic heart defects. J Pediatr. 2010;156(5):810-7. 817.e811-817.e814

14. Rauch R, Hofbeck M, Zweier C, Koch A, Zink S, Trautmann U, et al. Comprehensive genotype-phenotype analysis in 230 patients with tetralogy of Fallot. J Med Genet. 2010;47(5):321-31.

15. Breckpot J, Thienpont B, Arens $Y$, Tranchevent LC, Vermeesch JR, Moreau $Y$, et al. Challenges of interpreting copy number variation in syndromic and non-syndromic congenital heart defects. Cytogenet Genome Res. 2011; 135(3-4):251-9.

16. Goldmuntz E, Paluru P, Glessner J, Hakonarson H, Biegel JA, White PS, et al. Microdeletions and microduplications in patients with congenital heart disease and multiple congenital anomalies. Congenit Heart Dis. 2011;6(6):592-602.

17. Derwinska K, Bartnik M, Wisniowiecka-Kowalnik B, Jagla M, Rudzinski A, Pietrzyk $\mathrm{JJ}$, et al. Assessment of the role of copy-number variants in 150 patients with congenital heart defects. Med Wieku Rozwoj. 2012;16(3):175-82.

18. Bachman KK, Deward SJ, Chrysostomou C, Munoz R, Madan-Khetarpal S. Array CGH as a first-tier test for neonates with congenital heart disease. Cardiol Young. 2013:1-8

19. Syrmou A, Tzetis M, Fryssira H, Kosma K, Oikonomakis V, Giannikou K, et al Array comparative genomic hybridization as a clinical diagnostic tool in syndromic and nonsyndromic congenital heart disease. Pediatr Res. 2013; 73(6):772-6.

20. Yoon PW, Rasmussen SA, Lynberg MC, Moore CA, Anderka M, Carmichael SL, et al. The National Birth Defects Prevention Study. Public Health Rep. 2001;116(Suppl 1):32-40.

21. Rasmussen SA, Olney RS, Holmes LB, Lin AE, Keppler-Noreuil KM, Moore CA, et al. Guidelines for case classification for the National Birth Defects Prevention Study. Birth Defects Res A Clin Mol Teratol. 2003;67(3):193-201.

22. Botto LD, Lin AE, Riehle-Colarusso T, Malik S, Correa A. Seeking causes: classifying and evaluating congenital heart defects in etiologic studies. Birth Defects Res A Clin Mol Teratol. 2007;79(10):714-27.

23. Kearney HM, Thorland EC, Brown KK, Quintero-Rivera F, South ST. Working Group of the American College of medical genetics laboratory quality 
assurance C. American College of Medical Genetics standards and guidelines for interpretation and reporting of postnatal constitutional copy number variants. Genet Med. 2011;13(7):680-5.

24. Sagoo GS, Butterworth AS, Sanderson S, Shaw-Smith C, Higgins JP, Burton $\mathrm{H}$. Array $\mathrm{CGH}$ in patients with learning disability (mental retardation) and congenital anomalies: updated systematic review and meta-analysis of 19 studies and 13,926 subjects. Genet Med. 2009;11(3):139-46.

25. Shaffer LG, Rosenfeld JA, Dabell MP, Coppinger J, Bandholz AM, Ellison JW, et al. Detection rates of clinically significant genomic alterations by microarray analysis for specific anomalies detected by ultrasound. Prenat Diagn. 2012;32(10):986-95

26. Gijsbers AC, Schoumans J, Ruivenkamp CA. Interpretation of array comparative genome hybridization data: a major challenge. Cytogenet Genome Res. 2011;135(3-4):222-7.

27. Heilstedt HA, Ballif BC, Howard LA, Kashork CD, Shaffer LG. Population data suggest that deletions of $1 \mathrm{p} 36$ are a relatively common chromosome abnormality. Clin Genet. 2003:64(4):310-6.

28. Doyle AJ, Doyle JJ, Bessling SL, Maragh S, Lindsay ME, Schepers D, et al. Mutations in the TGF-beta repressor SKI cause Shprintzen-Goldberg syndrome with aortic aneurysm. Nat Genet. 2012;44(11):1249-54.

29. Sinha T, Wang B, Evans S, Wynshaw-Boris A, Wang J. Disheveled mediated planar cell polarity signaling is required in the second heart field lineage for outflow tract morphogenesis. Dev Biol. 2012;370(1):135-44.

30. Soemedi R, Wilson IJ, Bentham J, Darlay R, Topf A, Zelenika D, et al. Contribution of global rare copy-number variants to the risk of sporadic congenital heart disease. Am J Hum Genet. 2012;91(3):489-501.

31. Geng J, Picker J, Zheng Z, Zhang X, Wang J, Hisama F, et al. Chromosome microarray testing for patients with congenital heart defects reveals novel disease causing loci and high diagnostic yield. BMC Genomics. 2014;15(1):1127.

32. Cooper GM, Coe BP, Girirajan S, Rosenfeld JA, Vu TH, Baker C, et al. A copy number variation morbidity map of developmental delay. Nat Genet. 2011 43(9):838-46.

33. Ballif BC, Rosenfeld JA, Traylor R, Theisen A, Bader PI, Ladda RL, et al. Highresolution array $\mathrm{CGH}$ defines critical regions and candidate genes for microcephaly, abnormalities of the corpus callosum, and seizure phenotypes in patients with microdeletions of 1q43q44. Hum Genet. 2012; 131(1):145-56

34. Hoischen A, van Bon BW, Gilissen C, Arts P, van Lier B, Steehouwer M, et al. De novo mutations of SETBP1 cause Schinzel-Giedion syndrome. Nat Genet. 2010;42(6):483-5.

35. Kearney HM, Kearney JB, Conlin LK. Diagnostic implications of excessive homozygosity detected by SNP-based microarrays: consanguinity, uniparental disomy, and recessive single-gene mutations. Clin Lab Med. 2011;31(4):595-613. ix

36. Bamforth SD, Braganca J, Eloranta JJ, Murdoch JN, Marques FI, Kranc KR, et al. Cardiac malformations, adrenal agenesis, neural crest defects and exencephaly in mice lacking Cited2, a new Tfap2 co-activator. Nat Genet. 2001;29(4):469-74.

37. Henke N, Albrecht P, Pfeiffer A, Toutzaris D, Zanger K, Methner A. Stromal interaction molecule 1 (STIM1) is involved in the regulation of mitochondrial shape and bioenergetics and plays a role in oxidative stress. J Biol Chem. 2012;287(50):42042-52.

38. Schmitt JP, Kamisago M, Asahi M, Li GH, Ahmad F, Mende U, et al. Dilated cardiomyopathy and heart failure caused by a mutation in phospholamban. Science. 2003:299(5611):1410-3.

39. van Hengel J, Calore M, Bauce B, Dazzo E, Mazzotti E, De Bortoli M, et al Mutations in the area composita protein alphaT-catenin are associated with arrhythmogenic right ventricular cardiomyopathy. Eur Heart J. 2013;34(3): 201-10.

40. Bacchelli E, Ceroni F, Pinto D, Lomartire S, Giannandrea M, D'Adamo P, et al. A CTNNA3 compound heterozygous deletion implicates a role for alphaTcatenin in susceptibility to autism spectrum disorder. J Neurodev Disord. 2014;6(1):17.

41. Miller DT, Adam MP, Aradhya S, Biesecker LG, Brothman AR, Carter NP, et al. Consensus statement: chromosomal microarray is a first-tier clinical diagnostic test for individuals with developmental disabilities or congenital anomalies. Am J Hum Genet. 2010;86(5):749-64.

42. Gentile M, Di Carlo A, Volpe P, Pansini A, Nanna P, Valenzano MC, et al. FISH and cytogenetic characterization of a terminal chromosome 1q deletion: clinical case report and phenotypic implications. Am J Med Genet A. 2003; $117 \mathrm{~A}(3): 251-4$.
43. Hill AD, Chang BS, Hill RS, Garraway LA, Bodell A, Sellers WR, et al. A 2-Mb critical region implicated in the microcephaly associated with terminal 1q deletion syndrome. Am J Med Genet A. 2007;143A(15):1692-8.

44. Hiraki Y, Okamoto N, Ida T, Nakata Y, Kamada M, Kanemura Y, et al. Two new cases of pure 1q terminal deletion presenting with brain malformations. Am J Med Genet A. 2008;146A(10):1241-7.

45. Wagner N, Guengoer E, Mau-Holzmann UA, Maden Z, Hoopmann M, Abele $\mathrm{H}$, et al. Prenatal diagnosis of a fetus with terminal deletion of chromosome 1 (q43) in first-trimester screening: is there a characteristic antenatal 1q deletion phenotype? A case report and review of the literature. Fetal Diagn Ther. 2011:29(3):253-6.

46. Roberts AE, Cox GF, Kimonis V, Lamb A, Irons M. Clinical presentation of 13 patients with subtelomeric rearrangements and a review of the literature. Am J Med Genet A. 2004;128A(4):352-63.

47. Thierry G, Beneteau C, Pichon O, Flori E, Isidor B, Popelard F, et al. Molecular characterization of $1 \mathrm{q} 44$ microdeletion in 11 patients reveals three candidate genes for intellectual disability and seizures. Am J Med Genet A 2012;158A(7):1633-40.

48. Cho JH, Song ES, Kim HN, Oh BS, Choi YY. A chromosome 1q44 deletion in a 4-months-old girl; the first report in Korea. Korean J Pediatr. 2014;57(6): 292-6.

49. De Vries BB, Knight SJ, Homfray T, Smithson SF, Flint J, Winter RM. Submicroscopic subtelomeric 1qter deletions: a recognisable phenotype? J Med Genet. 2001;38(3):175-8.

\section{Submit your next manuscript to BioMed Central and we will help you at every step:}

- We accept pre-submission inquiries

- Our selector tool helps you to find the most relevant journal

- We provide round the clock customer support

- Convenient online submission

- Thorough peer review

- Inclusion in PubMed and all major indexing services

- Maximum visibility for your research

Submit your manuscript at www.biomedcentral.com/submit
) Biomed Central 